durch Ammoniak-Essigäther zerlegt werden muss, um dadurch stärkere Reactionen auf unverändertes Morphin zu erhalten.

Dass aber Morphin, auch noch 14 Tage nach der Aufnahme desselben, im Körper nachgewiesen werden kann, haben A. A nth eaume and A. Mouneyrat ${ }^{1}$ ) wahrzunehmen Gelegenheit gehabt, als sie die Leiche eines Morphinisten untersuchten der, 2 Wochen nachdem ihm das Morphium völlig entzogen war, plötzlich starb. Zur Ermittelung dieses Alkaloids bedienten sie sich des Verfahrens von Dragendorff ${ }^{2}$ ) mit geringen Abweichungen. Sie fanden es deutlich in der Leber, im Gehirn and in den Nieren, and zwar war es in der Leber in grösserer Menge vorhanden als in den beiden anderen Organen.

\title{
In Bezug auf die Nachweisung des Arsens in gerichtlichen
} Fällen weist E. Fricke ${ }^{3}$ ) darauf hin, dass die Prüfung mit Hülfe des Mr arsh'schen Apparates unter Umständen nicht ganz sicher ist, weil die zuweilen auch bei Abwesenheit von Arsen auftretenden dunklen Anflüge ${ }^{4}$ ) in der Glasröhre zu Täuschungen Anlass geben könnten. Er empfiehlt deshalb zur sicheren Entscheidung der Frage, ob Arsen vorhanden ist oder nicht, folgendes Verfahren:

Der nach der Zerstörung der organischen Substanz durch Einleiten von Schwefelwasserstoff in die filtrirte Flüssigkeit erhaltene Niederschlag wird in Schwefelammonium gelöst und "eingedampft. Der Rückstand wird mit Soda und Salpeter geschmolzen, die Schmelze mit Wasser aufgenommen und mit Schwefelsäure wiederum verdampft. In die Lösung dieses von jeglichen störenden Substanzen nun freien Eindampfungsrückstandes wird Schwefelwasserstoff eingeleitet. Entsteht hierdurch ein Niederschlag, so wird er weiter behandelt (also auch der Marsh schen Probe unterworfen) wenn nicht, ist die Abwesenheit von Arsen constatirt.

1) Comptes rendus 124, 1475 .

2) Dragend orff, Ermittelung von Giften, S. $143 \mathrm{ff}$. und S. 225 ff.

3) Pharm. Zeitung 1897, No. 45; durch pharm. Zeitschrift f. Russland 36, 305.

4) Ueber die Natur derselben gibt der Verfasser an, dass sie auf den Kohlegehalt des angewandten Zinks zurückzuführen seien, während nach der mir zugänglichen Quelle ich dje Anfü̈ge durch die Reduction des im Glas enthaltenen Siliciums erklärt haben soll. Letzteres ist ein Irrthum. Ich habe beobachtet, dass arsenhaltige Glasröhren braune Anflüge geben, wenn durch glühende Theile derselben Wasserstoff geleitet wird, während in arsenfreiem Glase der aus denselben Materialien bereitete Wasserstoff keinen Anflug bewirkte. (Diese Zeitschrift 22. 402.)

W. F.

$$
\text { B erich tig ung. }
$$

Im Jahrgang 38 dieser Zeitschrift, Seite 189, Zeile 7 und 6 v. u. lies: L. De Koningh" statt "L. L. de Koninck". 